\title{
Correction to: The Measurement of Disaster Recovery Efficiency Using Data Envelopment Analysis: An Application to Electric Power Restoration
}

\author{
Priscillia Hunt and Kelly Klima
}

\section{Correction to:}

Chapter 3 in: M. Lee, A. Najera Chesler (eds.), Research in Mathematics and Public Policy, Association for Women in Mathematics Series 23, https://doi.org/10.1007/978-3-030-58748-2_3

The original version of this chapter was inadvertently published without updating additional corrections from the author. Now, the corrections have been incorporated in chapter proof and front matter. 